\title{
Palmitic Acid Methyl Ester Enhances Adipogenic Differentiation in Rat Adipose Tissue-Derived Mesenchymal Stem Cells through a G Protein-Coupled Receptor-Mediated Pathway
}

\author{
Jian-Hong Lin, ${ }^{1,2}$ Huan-Hsin Chang, ${ }^{3}$ Wen-Sen Lee, ${ }^{4}$ Pei-Ching Ting, ${ }^{5}$ Yu-Po Luo, ${ }^{5}$ \\ and Kun-Ta Yang ${ }^{3,6}$ \\ ${ }^{1}$ PhD Program in Pharmacology and Toxicology, School of Medicine, Tzu Chi University, No. 701, Sec. 3, Zhongyang Rd., \\ Hualien, Taiwan \\ ${ }^{2}$ Division of Experimental Surgery, Department of Surgery, Hualien Tzu Chi Hospital, Buddhist Tzu Chi Medical Foundation, \\ No. 707, Sec. 3, Zhongyang Rd., Hualien, Taiwan \\ ${ }^{3}$ Master Program in Medical Physiology, School of Medicine, Tzu Chi University, No. 701, Sec. 3, Zhongyang Rd., Hualien, Taiwan \\ ${ }^{4}$ Graduate Institute of Medical Sciences, College of Medicine, Taipei Medical University, No. 250, Wuxing St., Taipei, Taiwan \\ ${ }^{5}$ Department of Surgery, Hualien Tzu Chi Hospital, Buddhist Tzu Chi Medical Foundation, No. 707, Sec. 3, Zhongyang Rd., \\ Hualien, Taiwan \\ ${ }^{6}$ Department of Physiology, School of Medicine, Tzu Chi University, No. 701, Sec. 3, Zhongyang Rd., Hualien, Taiwan
}

Correspondence should be addressed to Kun-Ta Yang; ktyang@mail.tcu.edu.tw

Received 22 March 2021; Revised 29 July 2021; Accepted 11 September 2021; Published 5 October 2021

Academic Editor: Qixiang Shao

Copyright ( 2021 Jian-Hong Lin et al. This is an open access article distributed under the Creative Commons Attribution License, which permits unrestricted use, distribution, and reproduction in any medium, provided the original work is properly cited.

\begin{abstract}
Adipogenic differentiation from stem cells has become a research target due to the increasing interest in obesity. It has been indicated that adipocytes can secrete palmitic acid methyl ester (PAME), which is able to regulate stem cell proliferation. However, the effects of PAME on adipogenic differentiation in stem cell remain unclear. Here, we present that the adipogenic differentiation medium supplemented with PAME induced the differentiation of rat adipose tissue-derived mesenchymal stem cells (rAD-MSCs) into adipocyte. rAD-MSCs were treated with PAME for 12 days and then subjected to various analyses. The results from the present study show that PAME significantly increased the levels of adipogenic differentiation markers, $\operatorname{PPAR} \gamma$ and Gpd1, and enhanced adipogenic differentiation in rAD-MSCs. Furthermore, the level of GPR40/120 protein increased during induction of adipocyte differentiation in rAD-MSCs. Cotreatment with PAME and a GPR40/120 antagonist together inhibited the PAME-enhanced adipogenic differentiation. Moreover, PAME significantly increased phosphorylation of extracellular signal-regulated kinases (ERK), but not AKT and mTOR. Cotreatment with PAME and a GPR40/120 antagonist together inhibited the PAME-enhanced ERK phosphorylation and adipogenic differentiation. PAME also increased the intracellular $\mathrm{Ca}^{2+}$ levels. Cotreatment with PAME and a $\mathrm{Ca}^{2+}$ chelator or a phospholipase C (PLC) inhibitor prevented the PAME-enhanced ERK phosphorylation and adipogenic differentiation. Our data suggest that PAME activated the GPR40/120/PLC-mediated pathway, which in turn increased the intracellular $\mathrm{Ca}^{2+}$ levels, thereby activating the ERK, and eventually enhanced adipogenic differentiation in rAD-MSCs. The findings from the present study might help get insight into the physiological roles and molecular mechanism of PAME in regulating stem cell differentiation.
\end{abstract}

\section{Introduction}

Obesity is a tremendous health problem worldwide. Excess adiposity is an established risk factor for metabolic diseases, heart diseases, hypertension, stroke, and several types of cancer [1]. Obesity is defined as an excessive accumulation of adipose tissue and can be divided into two main types: hyperplasia (adipocyte number increase) and hypertrophy 
(adipocyte size increase). However, several studies have demonstrated that the adipocyte number increases when body fat reaches $25 \%$ of the total body weight in children and adults [2, 3]. Interestingly, adipocyte precursors from obese subjects proliferate more rapidly in culture than the cells from lean individuals $[4,5]$. New adipocytes constantly arise from a preexisting population of undifferentiated progenitor cells. On the other hand, the mesenchymal stem cells (MSCs), a major source of adipocyte generation in adipose tissue, can increase adipocyte number $[1,6]$.

Adipose tissue is now recognized as an endocrine organ that secretes numerous adipokines and free fatty acids (FFAs). Previous studies have shown that adipose tissue environmental niche, in which adipose-derived mesenchymal stem cells (AD-MSCs) reside, has a profound impact on their differentiation capacity [7-9]. The adipocytes can secrete factors, such as sFRP-1 [10], chemerin [11], adiponectin [12], and leptin [13], to promote adipogenic differentiation. Similarly, the adipose tissue condition medium increases adipogenic differentiation of AD-MSCs. On the other hand, FFAs, such as palmitate [14], arachidonic acid [15], and linoelaidic acid [16], have been reported to enhance adipogenic differentiation in MSCs.

A recent study reported that perivascular adipose tissue releases PAME, causing vasorelaxation [17]. PAME, an endogenous fatty acid methyl ester (FAME), has been reported to possess potent antifibrotic [18-20] and antiinflammatory activities $[21,22]$ and regulates cell proliferation in MSCs [23-25]. PAME is detected in adipogenic differentiated mesenchymal stromal cells, but not in the undifferentiated mesenchymal stromal cells [26]. Taken together, these data suggest that PAME plays a critical role in the stem cell differentiation. However, the effects of PAME on the differentiation of stem cell into the adipocyte lineage remain unclear.

PAME has a structure similar to fatty acid, but its target molecule is still unclear. Several orphan G protein-coupled receptors (GPCRs), including GPR40, GPR43, GPR41, and GPR120, have been identified as receptors for free fatty acid and can be activated by free fatty acid and their derivatives. GPR43 and GPR41 are activated by short-chain fatty acids, whereas GPR40 and GPR120 are activated by medium- to long-chain fatty acids [27].

Ichimura et al. demonstrated in a human study that the level of GPR120 is significantly higher in obese individuals than in lean control [28]. Furthermore, the level of GPR120 mRNA increases during induction of adipocyte differentiation in 3T3-L1 cells [29]. Knockdown of GPR120 by siRNA or GPR120 gene deficiency suppresses the expression of adipogenic genes and lipid accumulation in 3T3-L1 cells and mouse embryonic fibroblast, respectively [28, 29]. Gao et al. also demonstrated that low concentrations of GPR120 agonists can increase the ability of adipogenic differentiation in MSCs [30]. However, the mechanism underlying PAME enhancing the GPR40/120-mediated adipocyte differentiation in rat AD-MSCs (rAD-MSCs) has not been elucidated. In the present investigation, we delineated the signaling pathway involved in the PAME-enhanced rADMSC adipogenic differentiation.

\section{Materials and Methods}

2.1. Chemicals. PAME, palmitic acid (PA), and stearic acid methyl ester (SAME) were purchased from Sigma-Aldrich (St. Louis, MO) and dissolved in 100\% methanol. DC260126, dexamethasone, L-ascorbate-2-phosphate, indomethacin, 1,2-bis (2-aminophenoxy)ethane-N,N, ${ }^{\prime}, \mathrm{N}^{\prime}$-tetraacetic acid tetra (acetoxymethyl ester) (BAPTA-AM), triethyl phosphate, and Oil Red $\mathrm{O}$ were purchased from Sigma-Aldrich. GW1100 was purchased from Cayman Chemical Company (Ann Arbor, MI), AH7614 was purchased from Abcam (Cambridge, England), U73122 was purchased from Millipore (Burlington, MA), and U0126 was purchased from Calbiochem (San Diego, CA).

2.2. Preparation and Expansion of $r A D$-MSCs. Adult male Sprague-Dawley rats (350-450 g) were used as adipose tissue donors. The rAD-MSCs were obtained from the adipose tissues of rats that were anesthetized using urethane $(1.5 \mathrm{~g} / \mathrm{kg}$, i.p.) and sacrificed. The protocol was approved by the Institution of Animal Care and Use Committee of the Tzu Chi University (IACUC Approval No. 107003). Adipose tissues were washed using phosphate-buffered saline (PBS) containing $1 \%$ penicillin/streptomycin (GIBCO; Grand Island, NY). The tissues were minced and digested with $0.1 \%$ collagenase type I (GIBCO) in PBS for $60 \mathrm{~min}$ at $37^{\circ} \mathrm{C}$, and collagenase was then inactivated with an equal amount of culture medium (DMEM-high glucose supplemented with $10 \%$ FBS and 1\% penicillin/streptomycin) (GIBCO). After centrifugation for $10 \mathrm{~min}$ at 2,000 rpm, the $\mathrm{rAD}-\mathrm{MSCs}$ were incubated at $37^{\circ} \mathrm{C}$ in a fully humidified atmosphere with $5 \% \mathrm{CO}_{2}$, and the culture medium was changed every $48 \mathrm{~h}$.

2.3. Adipogenic Differentiation. rAD-MSCs were seeded at a density of $1 \times 10^{4}$ cells $/ \mathrm{cm}^{2}$. Cells were incubated in a humidified incubator at $37^{\circ} \mathrm{C}$ with $5 \% \mathrm{CO}_{2}$. Adipocyte differentiation was induced by replacing culture medium with adipogenic induction medium (DMEM-high glucose supplemented with $10^{-7} \mathrm{M}$ dexamethasone, $50 \mu \mathrm{g} / \mathrm{mL}$ L-ascorbate2-phosphate, $10 \mu \mathrm{g} / \mathrm{mL}$ indomethacin, $10 \% \mathrm{FBS}$, and $1 \%$ penicillin/streptomycin). The adipogenic induction medium was changed every other day for 12 days.

2.4. Oil Red O Staining. rAD-MSCs were seeded in $24 \mathrm{~mm}$ poly-l-lysine-coated coverslips. After differentiation into adipocytes, adipogenic induction medium was removed and the cells were washed thrice with PBS. Cells were fixed in $10 \%$ formaldehyde for $30 \mathrm{~min}$ at room temperature and washed thrice with distilled water. Distilled water was then removed from the coverslips, and $500 \mu \mathrm{L}$ of Oil Red O working solution (from $3 \mathrm{~mL}$ of stock solution, which contains $250 \mathrm{mg}$ Oil Red $\mathrm{O}$ in $50 \mathrm{~mL} 60 \%$ triethyl phosphate, in $2 \mathrm{~mL}$ distilled water, and filtered through Whatman filter paper No. 1.) was added to each coverslip. Cells were stained for $10 \mathrm{~min}$ at room temperature and then washed thrice with distilled water. Cells were examined under the microscope, and images were captured at 10x magnifications using an Olympus CX31 microscope. For quantitation of lipid droplets, cells were extracted with $200 \mu \mathrm{L}$ of $60 \%$ triethyl phosphate for $10 \mathrm{~min}$, and absorbance was measured using 
Thermo Scientific Multiskan Spectrum ELISA plate reader (Thermo, Waltham, MA) at $490 \mathrm{~nm}$.

2.5. Western Blot Analysis. rAD-MSCs were washed twice with PBS and lysed in RIPA lysis buffer (Millipore) containing $1 \%$ protease inhibitor (Calbiochem) and $0.5 \%$ phosphatase inhibitor (Calbiochem). The lysates were clarified by centrifugation at $12,000 \mathrm{rpm}$ for $15 \mathrm{~min}$ at $4^{\circ} \mathrm{C}$. Electrophoresis sample buffer ( $1 \mathrm{M}$ Tris- $\mathrm{HCl}, \mathrm{pH} 6.8 ; 5 \% 2$ mercaptoethanol; $20 \%$ glycerol; $10 \%$ SDS; and $0.5 \%$ bromophenol blue) was added to the cell lysates and boiled for $10 \mathrm{~min}$ at $110^{\circ} \mathrm{C}$. The protein sample $(30 \mu \mathrm{g})$ was loaded into a $10 \%$ SDS-polyacrylamide gel, subjected to electrophoresis, and then transferred to PVDF membrane (Millipore). The membrane was treated with 5\% BSA in Tween-Trisbuffered saline (T-TBS) buffer $(0.05 \%$ Tween $20 ; 200 \mathrm{mM}$ Tris- $\mathrm{HCl}, \mathrm{pH} 7.4$; and $1.5 \mathrm{M} \mathrm{NaCl}$ ) for $1 \mathrm{~h}$ at room temperature to block the nonspecific IgGs and then incubated with primary antibodies diluted in T-TBS buffer overnight at $4^{\circ} \mathrm{C}$. The information of primary and secondary antibodies used in this study is shown as follows: all primary antibodies including anti-PPAR $\gamma$, anti-p-ERK1/2, anti-ERK1/2, anti-pAKT, anti-AKT, anti-p-mTOR, and anti-mTOR purchased from Cell Signaling (Danvers, MA); anti-GPR40 purchased from Boster Bio (Pleasanton, CA); and anti-GPR120 purchased from Novus Biologicals (Centennial, CO) were in 1,000 dilution; anti- $\beta$-actin purchased from Millipore was in 10,000 dilution. Secondary antibodies (peroxidase-conjugated goat anti-rabbit IgG or anti-mouse IgG) were diluted in T-TBS buffer $(1: 5,000)$, and the immunoreactive proteins were visualized with an ECL detection system (GE Healthcare; Uppsala, Sweden). The resulting bands were analyzed using Image-Pro Plus software and normalized using $\beta$-actin.

2.6. Quantitative Real-Time PCR. Total RNAs were extracted from rAD-MSCs using the Trizol reagent (Ambion; Carlsbad, CA), and the cDNA was synthesized with Verso ${ }^{\mathrm{TM}}$ cDNA Kit (Thermo) using $3 \mu \mathrm{g}$ of total RNAs. The quantitation of cDNA amount was performed with quantitative real time-PCR using a Maxima SYBR Green qPCR Master Mix (2x) and ROX Solution (Thermo) and then detected using the LightCycler 480 System (Roche; Basel, Switzerland). The following PCR primers were used: Ppar $\gamma$, forward: $5^{\prime}$-TTG AGT GCC GAG TCT GTG GGG ATA A-3', reverse: $5^{\prime}$-CAG GGA GGC CAG CAT CGT GTA GA-3'; Gpd1, forward: $5^{\prime}$-AAC AAT GAC CAC GAA AAC GTG A-3', reverse: $5^{\prime}$-GTG AGG GAT GAC GAA CAC CA-3'; Gapdh, forward: $5^{\prime}$ - ATG TTC CAG TAT GAC TCC ACT CAC G-3', reverse: $5^{\prime}$ GAA GAC ACC AGT AGA CTC CAC GAC A- $3^{\prime}$. All gene expression was analyzed using the comparative $C_{\mathrm{t}}$ method $\left(2^{-\Delta \Delta \mathrm{Ct}}\right)$, where $\Delta \Delta C_{\mathrm{t}}=\Delta C_{\mathrm{t}}($ sample $)-\Delta C_{\mathrm{t}}$ (reference) relative to Gapdh levels.

2.7. Flow Cytometry. rAD-MSCs were incubated with $\mathrm{N}$-2-hydroxy-ethylpiperazine- $\mathrm{N}^{\prime}$-2-ethanesulphonic acid(HEPES-) buffered Tyrode solution (NT) containing $2.5 \mu \mathrm{M}$ Fluo-3-AM (Invitrogen; Carlsbad, CA. USA) for $30 \mathrm{~min}$ at room temperature. Intracellular $\mathrm{Ca}^{2+}$ analyses were carried out using Gallios ${ }^{\mathrm{TM}}$ Flow Cytometer (Beckman Coulter; Brea, CA. USA). The excitation/emission was detected at $488 / 525 \mathrm{~nm}$ wavelength.

2.8. Statistical Analyses. Data from at least three independent experiments were presented as means \pm SEM and compared with unpaired $t$-test. Data obtained from three or more groups were subjected to one-way ANOVA followed by Fisher's least significant difference test, and statistical value of ${ }^{*} p<0.05$ was considered significant.

\section{Results}

3.1. Effects of PAME on rAD-MSC Adipogenic Differentiation. Initially, we examined the effect of PAME on $\mathrm{rAD}-\mathrm{MSC}$ adipogenic differentiation. Treatment with PAME $(30,50$, or $100 \mu \mathrm{M})$ significantly enhanced rADMSC adipogenic differentiation (Figures $1(\mathrm{a})$ and $1(\mathrm{~b})$ ). The enhancement of PAME on the rAD-MSC adipogenic differentiation was confirmed by examining the mRNA and protein levels of adipogenic differentiation markers, peroxisome proliferator-activated receptor gamma (Ppary), and glycerol-3-phosphate dehydrogenase 1 (Gpd1), in rADMSCs treated with or without PAME $(50 \mu \mathrm{M})$. Quantitative RT-PCR assay demonstrated that the mRNA levels of both Ppary (Figure 1(c)) and Gpd1 (Figure 1(d)) were significantly increased in the PAME-treated group as compared with the adipogenic induction medium-treated control group. The protein levels of PPAR $\gamma$ detected by Western blot analyses also increased in the PAME-treated group (Figure 1(e)). PAME $(50 \mu \mathrm{M})$ significantly enhanced rADMSC adipogenic differentiation, and this enhancement was blocked by $0.5 \%$ BSA (Figure $1(\mathrm{f})$ ). To further examine the specificity of PAME on rAD-MSC adipogenic differentiation, the adipogenic differentiation effect of SAME, a structural analog of FAME, and PA, a precursor of PAME, was tested to serve as negative controls. As shown in (Figure $1(\mathrm{~g}))$, treatment with SAME $(50 \mu \mathrm{M})$ or PA $(50 \mu \mathrm{M})$ for 12 days did not significantly affect the adipogenic differentiation of rAD-MSCs.

3.2. Involvement of GPR40 and GPR120 in the PAMEInduced rAD-MSC Adipogenic Differentiation. The G protein-coupled receptors GPR40 and GPR120, also known as FFAR1 and FFAR4, respectively, are known to be activated by medium- to long-chain fatty acids [27]. Moreover, GPR40 has been shown to be the sensor of C10 methyl ester [31]. Accordingly, we examined whether GPR40/120 are involved in the PAME-enhanced rAD-MSC adipogenic differentiation. rAD-MSCs were induced to differentiate into adipocytes under the adipogenic induction medium. After induction of adipogenic differentiation with adipogenic induction medium for 12 days, the protein levels of both GPR40 (Figure 2(a)) and GPR120 (Figure 2(b)) were significantly increased in $\mathrm{rAD}-\mathrm{MSC}$ treated with or without PAME $(50 \mu \mathrm{M})$ group as compared with the cells treated with culture medium. Lipid droplets were stained with Oil Red $\mathrm{O}$, and quantification of the staining was performed. As shown in Figures 2(c) and 2(d), treatment with PAME 


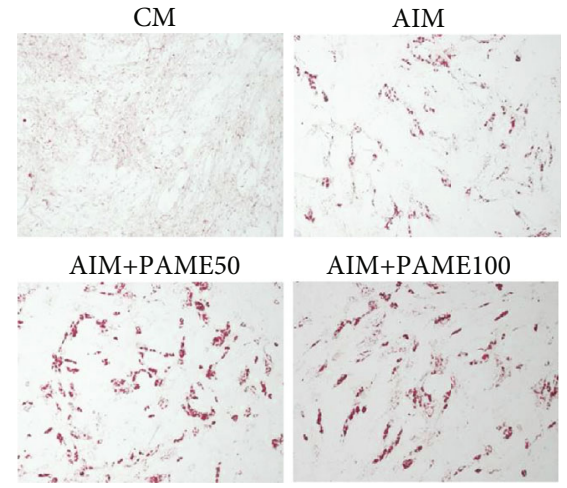

(a)

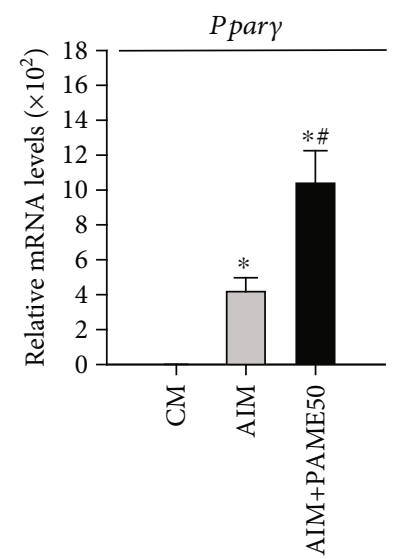

(c)

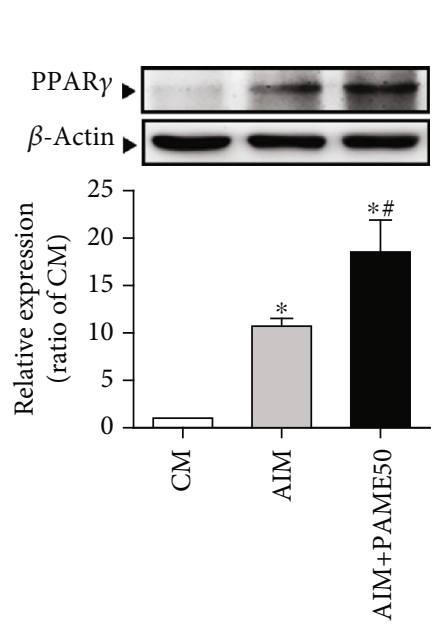

(e)

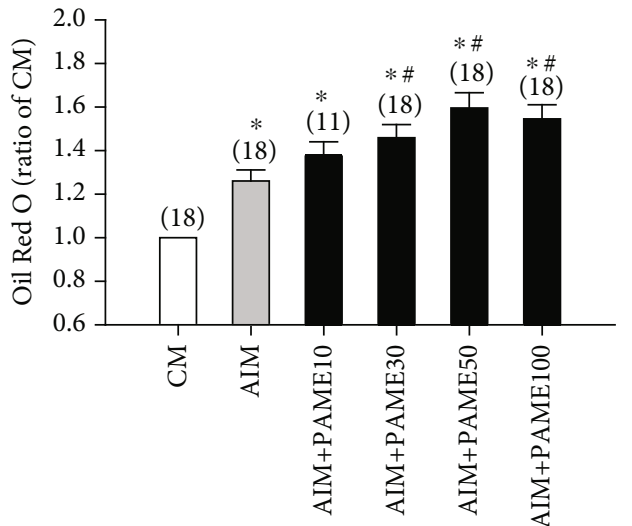

(b)

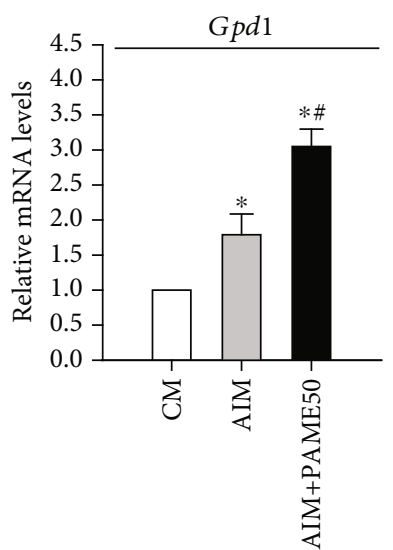

(d)

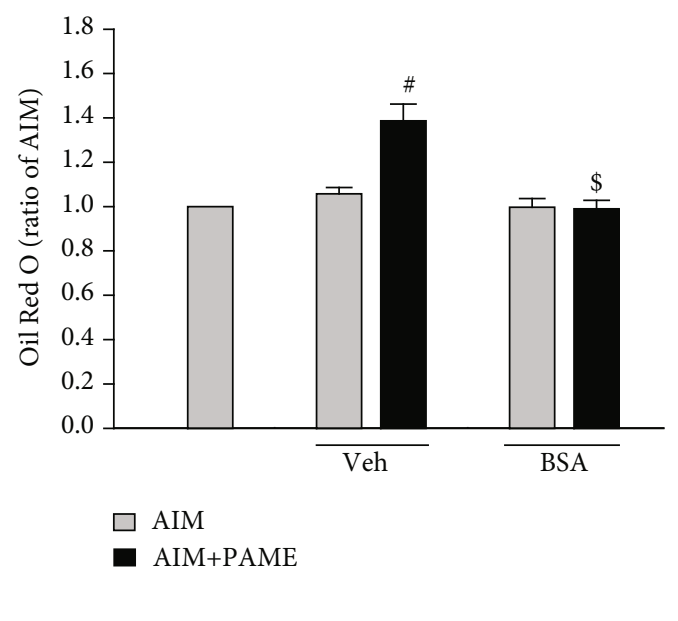

(f)

Figure 1: Continued. 


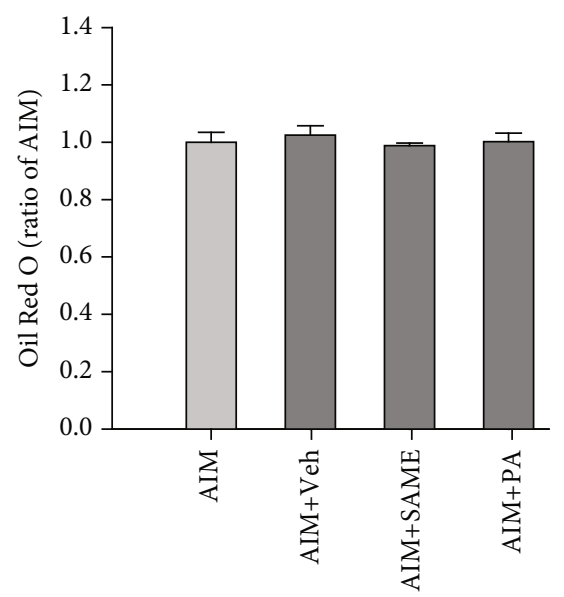

(g)

FIGURE 1: PAME increases adipogenic differentiation in rAD-MSCs. Treatment with PAME (10-100 $\mu \mathrm{M})$ in adipogenic induction medium for 12 days enhanced rAD-MSC adipogenic differentiation evidenced by Oil Red O staining (a) and quantitation of lipid droplets (b). Values shown in parentheses represent the number in each group. PAME $(50 \mu \mathrm{M})$ significantly increased the mRNA levels of $P p a r \gamma(\mathrm{c})(n=10)$ and Gpd1 (d) $(n=11)$ and the protein level of PPAR $\gamma(\mathrm{e})(n=5)$. (f) The effect of PAME on adipogenic differentiation was blocked by $0.5 \%$ BSA $(n=5)$. (g) Veh $(0.1 \%$ methanol), SAME $(50 \mu \mathrm{M})$, and PA $(50 \mu \mathrm{M})$ did not enhance adipogenic differentiation of rAD-MSCs $(n=10)$. All data represent mean \pm SEM. ${ }^{*} p<0.05$, versus the CM group; ${ }^{*} p<0.05$, versus the AIM group; ${ }^{\$} p<0.05$, versus the AIM+PAME group. CM: culture medium; AIM: adipogenic induction medium; BSA: bovine serum albumin; Veh: vehicle.

$(50 \mu \mathrm{M})$ enhanced the rAD-MSC adipogenic differentiation, and this effect was abolished by cotreatment with a GPR40 antagonist (DC260126 or GW1100) or a GPR120 antagonist (AH7614). To confirm the enhancement effect of PAME on the $\mathrm{rAD}-\mathrm{MSC}$ adipogenic differentiation, the mRNA levels of the adipogenic differentiation markers, Ppary and Gpd1, in $\mathrm{rAD}$-MSCs were examined. Quantitative RT-PCR assay demonstrated that the mRNA levels of Ppary (Figure 2(e)) and Gpd1 (Figure 2(f)) were significantly decreased in the cells cotreated with PAME $(50 \mu \mathrm{M})$ and GW1100 or AH7614 as compared with the PAME-treated group.

\subsection{Involvement of the PLC/ERK-Mediated Pathway in the} PAME-Enhanced rAD-MSC Adipogenic Differentiation. Since GPR40 and GPR120 were coupled with Gq protein, subsequently activating the PI3K-AKT or ERK1/2 signaling pathway, which has been shown to be involved in stem cell differentiation $[30,32]$, and mTOR is a downstream protein of PI3K-AKT signaling pathway, it has been demonstrated that mTOR upregulates adipogenic transcriptional factors [33]; we further investigated whether the PI3K-AKTmTOR or ERK1/2 signaling pathway is involved in the PAME-enhanced rAD-MSC adipogenic differentiation. Western blot analyses demonstrated that the level of $\mathrm{p}$ ERK1/2 (Figure 3(b)), but not p-AKT and p-mTOR (Figure 3(a)), was increased by PAME $(50 \mu \mathrm{M})$ treatment. Cotreatment with PAME $(50 \mu \mathrm{M})$ and an ERK inhibitor, U0126 $(5 \mu \mathrm{M})$, abolished the PAME-enhanced phosphorylation of ERK1/2, suggesting that the PAME-enhanced rADMSC adipogenic differentiation might be mediated through activating the ERK1/2 signaling pathway. GPR40 and GPR120 were originally reported as receptors coupled with Gq protein [27] that activates phospholipase C (PLC), resulting in increased intracellular $\mathrm{Ca}^{2+}$ levels by inositol 1,4,5-trisphosphate- $\left(\mathrm{IP}_{3^{-}}\right)$or diacylglycerol-induced phosphorylation of protein kinase $\mathrm{C}$ (PKC). Therefore, determination of intracellular $\mathrm{Ca}^{2+}$ levels is employed to check for activation of GPR40 and GPR120. Activation of ERK1/2 has been confirmed as one of the downstream signaling cascades of GPR40-Gq and GPR120-Gq proteins signaling. We examined whether PAME increased the phosphorylation of ERK1/2 through activation of GPR40 and GPR120. As shown in (Figure 3(c)), cotreatment with PAME $(50 \mu \mathrm{M})$ and GW1100 or AH7614 together abolished the PAMEenhanced phosphorylation of ERK1/2. We further investigated the ERK1/2 upstream molecules. As shown in (Figure $3(\mathrm{~d}))$, cotreatment with PAME $(50 \mu \mathrm{M})$ and U73122 $(2 \mu \mathrm{M})$, a PLC inhibitor, or BAPTA-AM $(0.5 \mu \mathrm{M}), \mathrm{a} \mathrm{Ca}^{2+}$ chelator, abolished the PAME-induced phosphorylation of ERK1/2. The concentration of GW1100, AH7614, U73122, or BAPTA-AM used in this study did not affect the levels of $\mathrm{p}$-ERK1/2 in rAD-MSCs after induction of adipogenic differentiation for 12 days (Supplement 1(a)). We also examined the intracellular $\mathrm{Ca}^{2+}$ levels in the PAME-treated $\mathrm{rAD}$ MSCs by flow cytometric analysis using Fluo-3, an intracellular $\mathrm{Ca}^{2+}$ indicator. As shown in (Figures 4(a) and 4(b)), treatment with PAME $(50 \mu \mathrm{M})$ significantly increased the level of Fluo-3, and this effect was abolished by cotreatment with GW1100, AH7614, U73122, or BAPTA-AM. Moreover, cotreatment with PAME $(50 \mu \mathrm{M})$ and U73122, BAPTAAM, or U0126 together also significantly reduced the PAME-enhanced adipogenic differentiation by Oil Red O staining, an indicator for adipogenic differentiation, in rAD-MSCs (Figures 5(a) and 5(b)). The PAME-increased mRNA levels of Ppary (Figure 5(c)) and Gpd1 (Figure 5(d)) and protein levels of PPAR $\gamma$ were abolished in the cells cotreated with PAME and GW1100, AH7614, U73122, U0126, or BAPTA-AM (Figure 5(e)). The concentrations of 

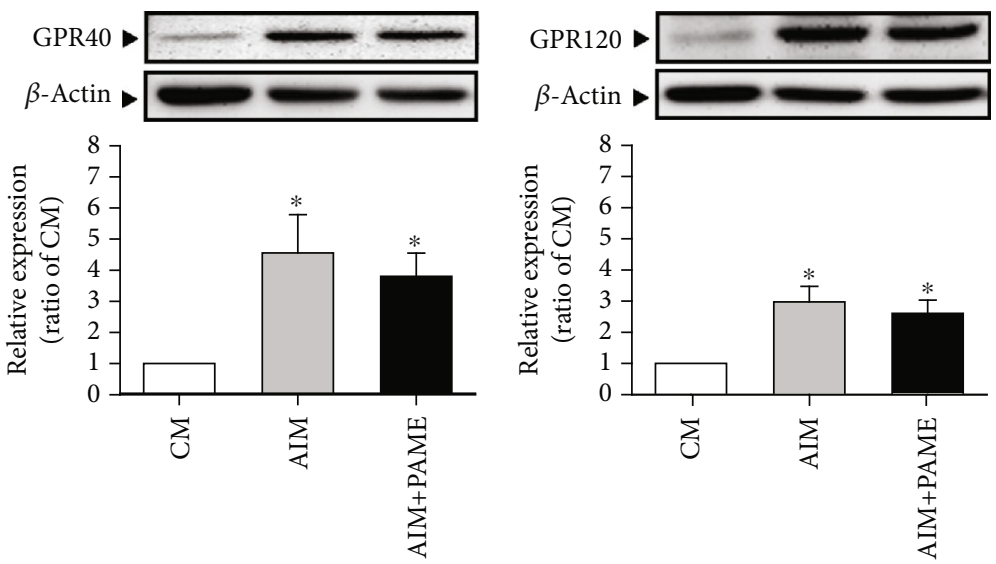

(a)

(b)
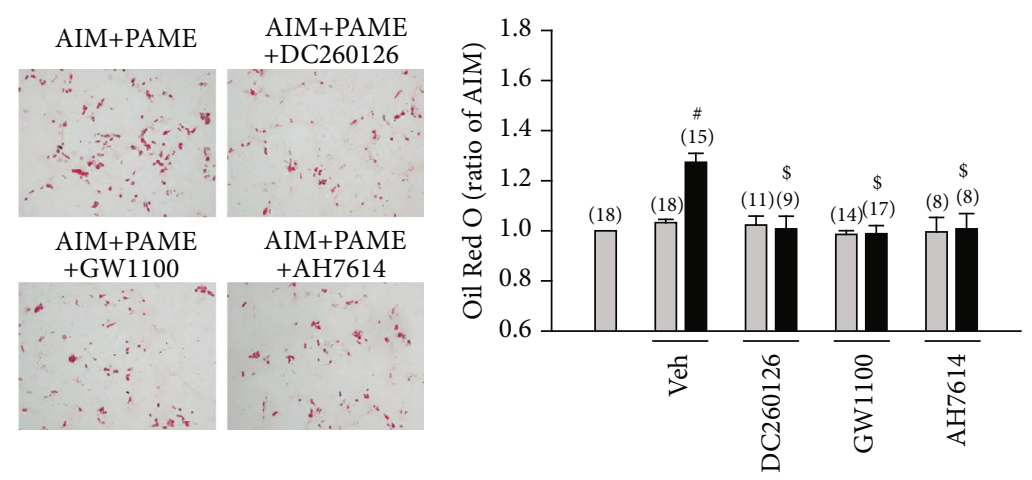

$\square$ AIM

- AIM+PAME

(c)

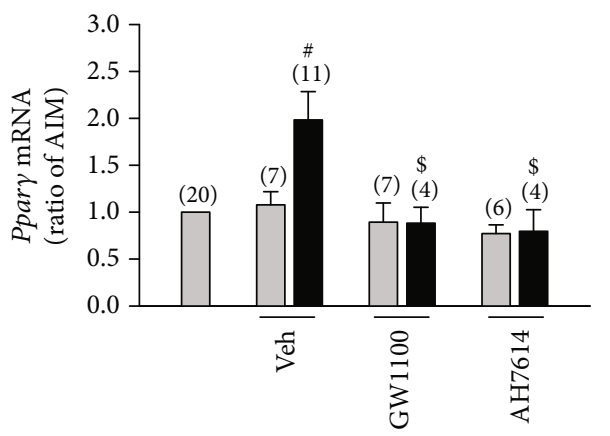

(d)

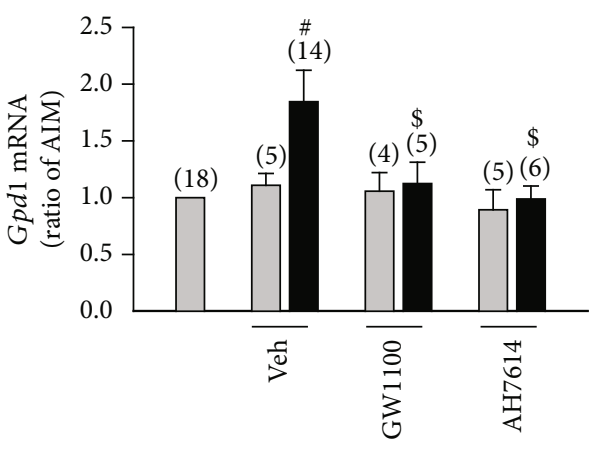

$\square$ AIM

- AIM+PAME

$\square$ AIM

- AIM+PAME

(e)

(f)

FIGURE 2: PAME activates the ERK1/2 pathway through stimulating the GPR40/120 in rAD-MSC adipogenic differentiation. Treatment with or without PAME $(50 \mu \mathrm{M})$ in adipogenic induction medium for 12 days enhanced the protein levels of GPR40 (a) and GPR120 (b) $(n=8)$. PAME $(50 \mu \mathrm{M})$ significantly enhanced the adipogenic differentiation, and this effect was inhibited by cotreatment with $5 \mu \mathrm{M}$ of GPR40 antagonist (DC260126 or GW1100) or $5 \mu \mathrm{M}$ of GPR120 antagonist (AH7614) (c, d). These antagonists were dissolved in 0.1\% DMSO (vehicle). PAME significantly increased the mRNA levels of Ppary (e) and Gpd1 (f), and these effects were abolished by cotreatment with GW1100 or AH7614. Values shown in parentheses represent the number in each group. All data represent mean \pm SEM. ${ }^{*} p<0.05$, versus the CM group; ${ }^{*} p<0.05$, versus the AIM group; ${ }^{\$} p<0.05$, versus the AIM+PAME group. CM: culture medium; AIM: adipogenic induction medium; Veh: vehicle. 


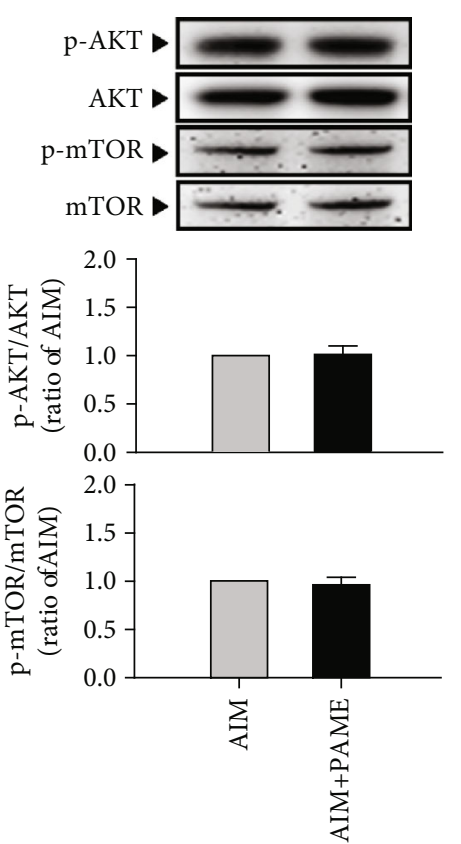

(a)
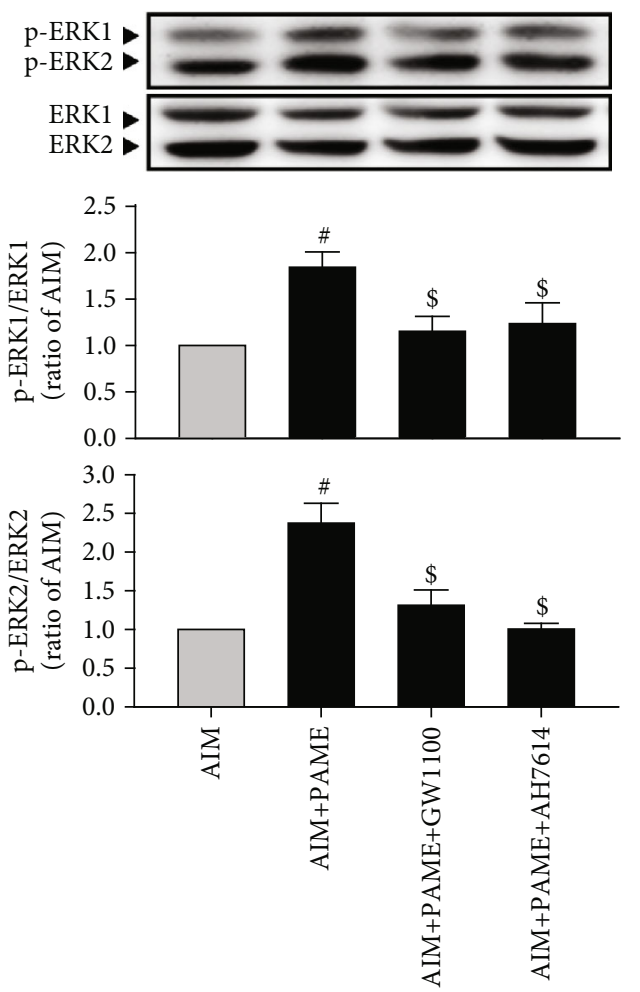

(c)
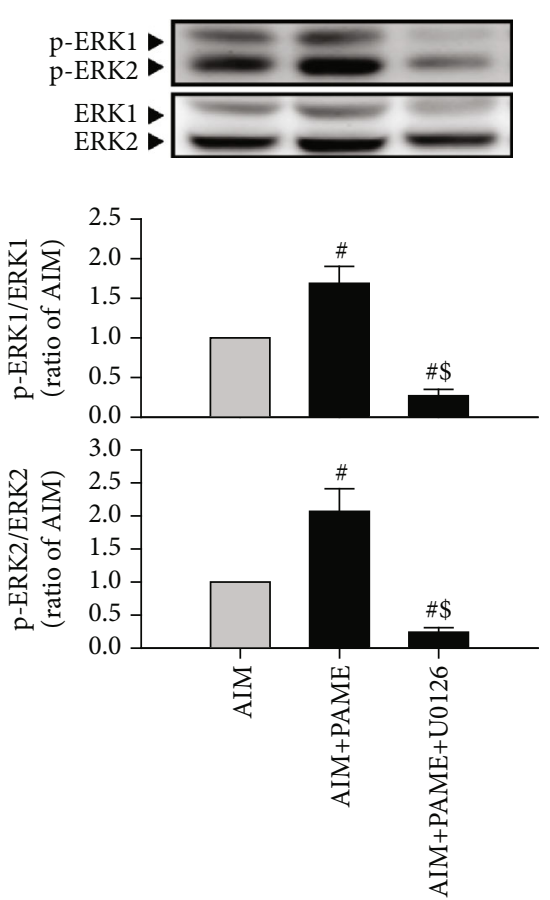

(b)
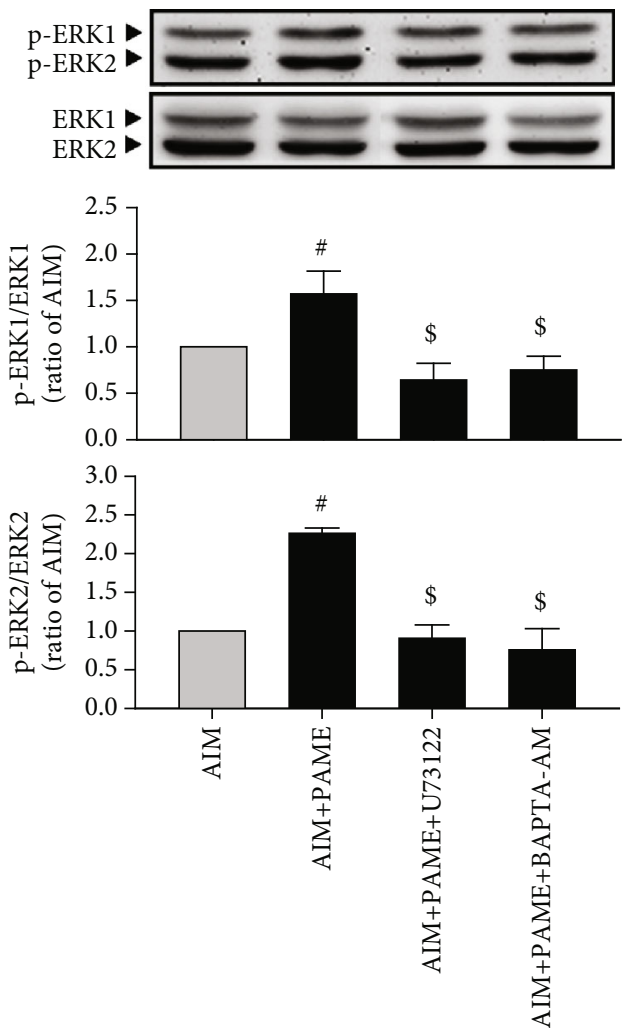

(d)

FIGURE 3: PAME activates the PLC-mediated signaling pathway through stimulating the GPR40/120 in rAD-MSCs. Treatment with PAME $(50 \mu \mathrm{M})$ in adipogenic induction medium for 12 days did not activate AKT and mTOR (a) $(n=12)$ but induced ERK1/2 activation (b) $(n=6)$. The PAME-induced ERK1/2 activation was abolished by cotreatment with ERK1/2 inhibitor (U0126). PAME (50 $\mu \mathrm{M})$ increased the levels of p-ERK1/2, and these effects were abolished by cotreatment with GW1100, AH7614 (c) $(n=4)$, U73122, or BAPTA-AM (d) $(n=4)$. All data represent mean \pm SEM. ${ }^{\#} p<0.05$, versus the AIM group; ${ }^{\$} p<0.05$, versus the AIM+PAME group. AIM: adipogenic induction medium. 


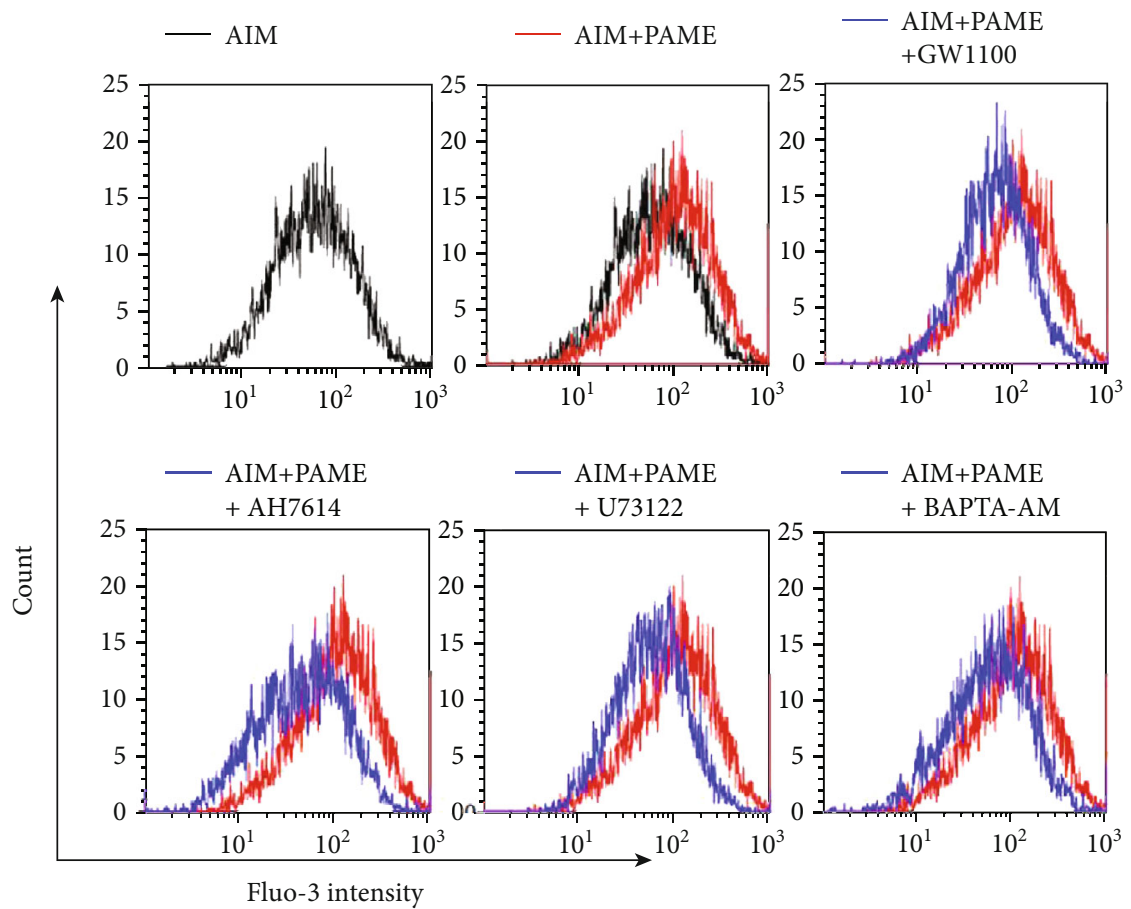

(a)

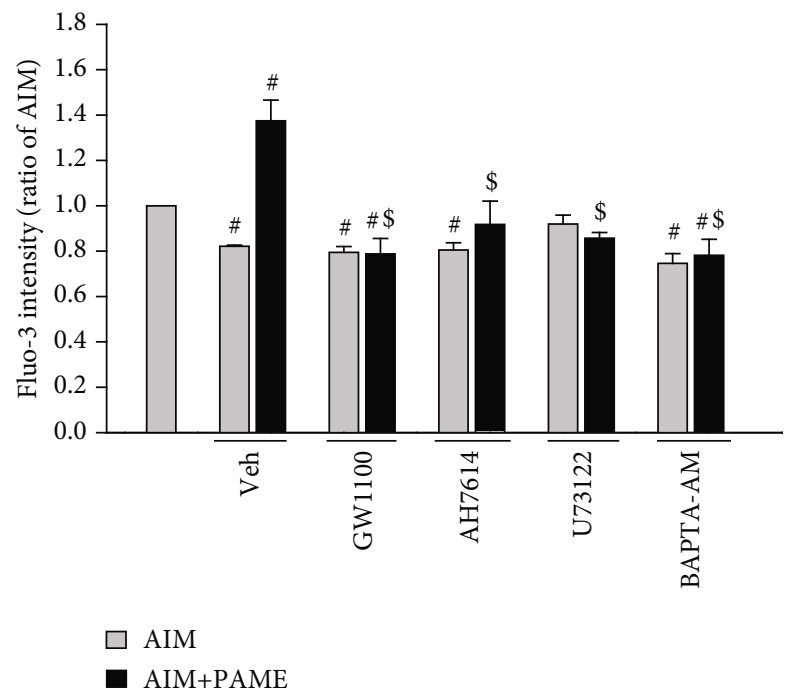

(b)

FIgURE 4: PAME increases intracellular $\mathrm{Ca}^{2+}$ through stimulating the GPR40/120 and activating the PLC-mediated signaling pathway in rAD-MSCs. Treatment with PAME $(50 \mu \mathrm{M})$ in adipogenic induction medium for 12 days increased the intracellular Ca ${ }^{2+}$ in $\mathrm{rAD}-\mathrm{MSCs}$, and these effects were abolished by cotreatment with GW1100, AH7614, U73122, or BAPTA-AM. (a) Representative histograms show the distribution of Fluo-3 fluorescence intensities, an indicator of intracellular $\mathrm{Ca}^{2+}$. (b) Quantitation fluorescence intensity of intracellular $\mathrm{Ca}^{2+}$ levels. All data represent mean \pm SEM $(n=5)$. These antagonists were dissolved in $0.1 \%$ DMSO (vehicle). ${ }^{\#} p<0.05$, versus the AIM group; ${ }^{\$} p<0.05$, versus the AIM+PAME group. AIM: adipogenic induction medium; Veh: vehicle.

these blockers used in this study did not affect protein levels of PPAR $\gamma$ in rAD-MSCs after induction of adipogenic differentiation for 12 days (supplement 1(b)).

\section{Discussion}

PAME, a fatty acid ester of palmitic acid in mammalian cells, represents an endogenous naturally occurring FAME [34]. It has been reported that endogenous PAME is released from superior cervical ganglion [35], retinal [36], and perivascular adipose tissue [17]. Liu et al. showed that PAME was synthesized through PA methylation via the AdoMet-dependent catechol-O-methyltransferase catalytic pathway in adipocytes [37]. Recently, we detected PAME in the rat bone marrow [25]. Lee et al. reported that the culture medium of differentiated adipocytes of NIH 3T3 and 3T3-L1 cells 


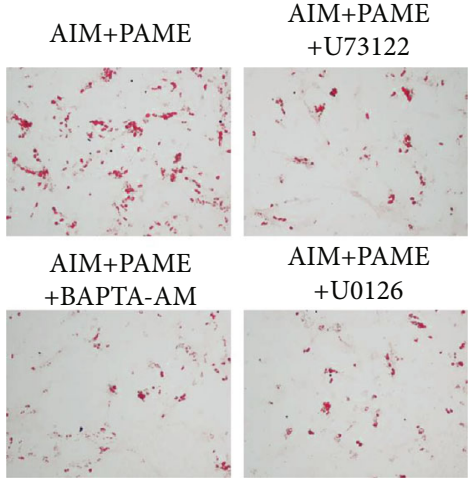

(a)

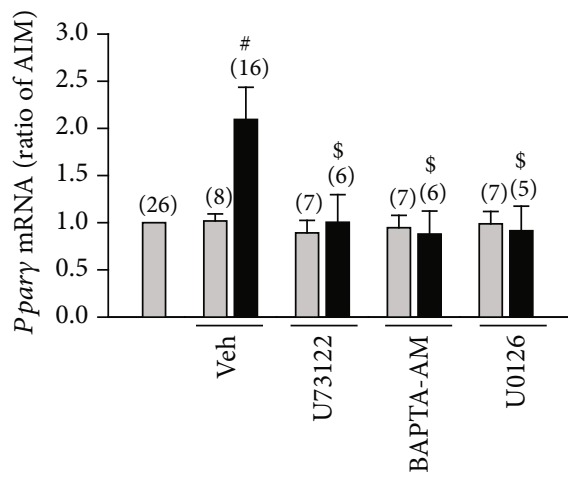

$\square$ AIM

- AIM+PAME

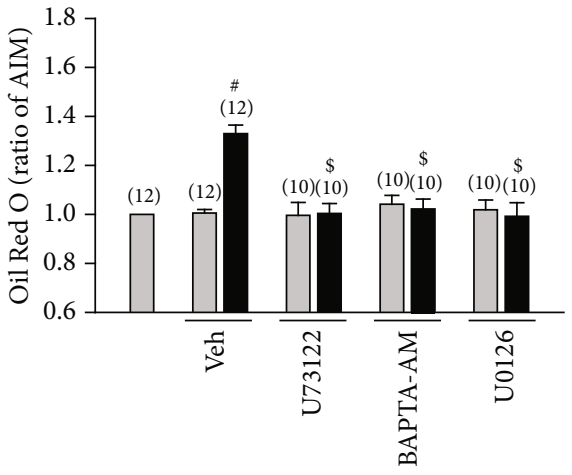

$\square$ AIM

- AIM+PAME

(b)

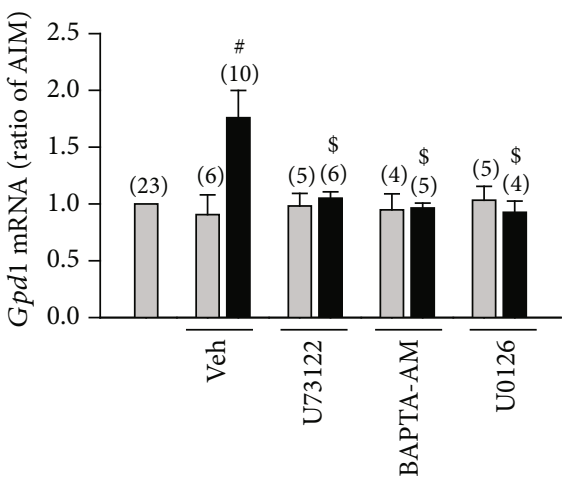

$\square \mathrm{AIM}$

- AIM+PAME

(c)

(d)

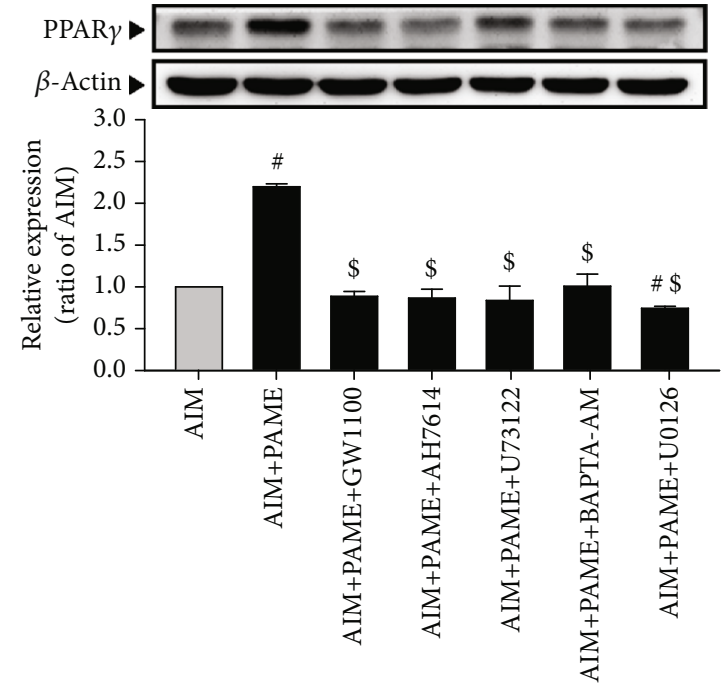

(e)

FIGURE 5: PAME increases adipogenic differentiation through activating the GPR40/120/PLC/ERK pathway. Treatment of rAD-MSCs with PAME $(50 \mu \mathrm{M})$ in adipogenic induction medium for 12 days enhanced the adipogenic differentiation, and these effects were abolished by cotreatment with U73122, U0126, or BAPTA-AM (a, b). PAME $(50 \mu \mathrm{M})$ significantly increased the mRNA levels of Ppary (c) and Gpd1 (d) in rAD-MSCs, and these effects were abolished by cotreatment with U73122, BAPTA-AM, or U0126. These antagonists were dissolved in $0.1 \%$ DMSO (vehicle). Values shown in parentheses represent the number in each group. PAME (50 $\mu \mathrm{M})$ increased the protein levels of PPAR $\gamma$ in rAD-MSCs, and these effects were abolished by cotreatment with GW1100, AH7614, U73122, BAPTA-AM, or U0126 (e) $(n=3)$. All data represent mean \pm SEM. ${ }^{\#} p<0.05$, versus the AIM group; ${ }^{\$} p<0.05$, versus the AIM+PAME group. AIM: adipogenic induction medium; Veh: vehicle. 


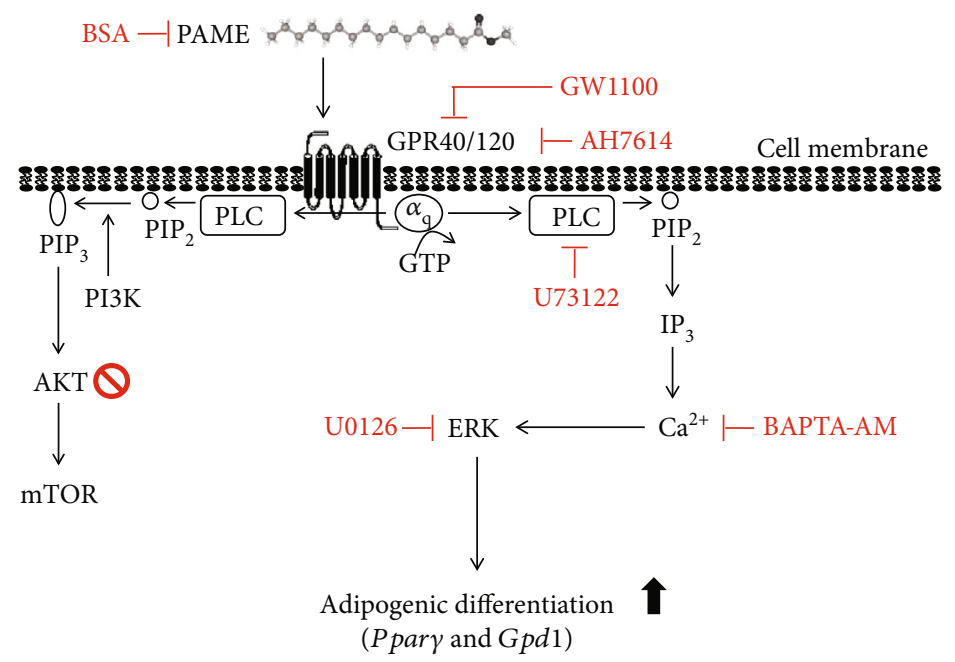

$r A D-M S C s$

FIGURE 6: Schematic representation of the PAME-enhanced adipogenic differentiation in rAD-MSCs. PAME stimulated the GPR40 and GPR120, subsequently activating PLC, which in turn caused $\mathrm{IP}_{3}$ generation, thereby leading to ERK1/2 activation through increases of intracellular $\mathrm{Ca}^{2+}$ levels, and eventually increased the expression of adipogenic differentiation genes, Ppar $\gamma$ and Gpd1.

contained a significant concentration of PAME [17]. PAME has been shown to inhibit phagocytosis $[38,39]$, fibrotic effects [18-20], inflammation [21,22], and oxidative stress [40]; to induce vasodilation $[17,35,36,41,42]$; and to prevent nonalcoholic steatohepatitis [43]. In stem cells, PAME is able to induce cell cycle arrest at the $G_{2} / M$ phase in hBM-MSCs [25]. However, the molecular mechanisms underlying PAME-induced stem cell differentiation are still unclear. In the present study, we demonstrated that PAME activated the GPR40/120/PLC/ERK signaling pathway, leading to the enhancement of adipogenic differentiation in rAD-MSCs.

p53, also known as a tumour suppressor protein, can regulate cell cycle and promote differentiation of human embryonic stem cells and 3T3-L1 cells [44-48]. We previously showed that PAME was able to induce cell cycle arrest at the $G_{2} / M$ phase in hBM-MSCs via the p53/p21 pathway [25]. p53 can regulate the MAPK signaling pathways [49] and lead to accelerated differentiation of PC12 cells mediated by activation of the MAPK cascade [50]. In the present study, we demonstrated that PAME activated the PLC/ERK signaling pathway, leading to the enhancement of adipogenic differentiation in rAD-MSCs. It has been demonstrated that activation of the MEK/ERK signaling promotes adipogenesis by enhancing Ppary and Clebp $\alpha$ gene expression during the differentiation of 3T3-L1 preadipocytes [51]. ERK1 and ERK2 are involved in recruitment and maturation of hBM-MSCs induced to adipocyte differentiation $[52,53]$.

Calcium performs the physiological functions in cells by activating various intracellular signaling pathways. It is involved in several cell functions including apoptosis, exocytosis, and gene activation during the differentiation and/or proliferation processes. It has been demonstrated that increasing calcium in the early stages of differentiation inhibits human adipocyte differentiation, whereas increasing calcium in the late stage promotes human adipocyte differentiation and increases expression of PPAR $\gamma$, an adipogenic differentiation transcription factor [54]. In the present study, we demonstrated that PAME significantly increased the intracellular calcium levels, and cotreatment with BAPTA$\mathrm{AM}$, a $\mathrm{Ca}^{2+}$ chelator, abolished the PAME-enhanced adipogenic differentiation of rAD-MSCs and decreased the levels of Ppary and Gpd1 mRNA. It has been demonstrated that exogenous calcium treatment enhanced the adipogenic differentiation of human umbilical cord blood-derived mesenchymal stem cells via negatively regulating the Wnt5a/ $\beta$-catenin signaling pathway [55]. In the present study, we demonstrated that PAME activated the PLC/ERK signaling pathway, and cotreatment with U73122 (a PLC inhibitor) or U0126 (an ERK inhibitor) abolished the PAME-enhanced adipogenic differentiation of rAD-MSCs and decreased the levels of Ppary and Gpd1 mRNA. Interaction between ERK and $\mathrm{Wnt} / \beta$ catenin pathway can regulate proliferation and differentiation in embryonic stem cells $[56,57]$. It has been demonstrated that stimulating the MEK-ERK pathway results in the activation of the $\mathrm{Wnt} / \beta$-catenin pathway, leading to the differentiation of human embryonic stem cell towards the endoderm lineage [58]. Tian et al. showed that blockade of the ERK1/2 activity inactivates the $\mathrm{Wnt} / \beta$-catenin signaling in the BM-MSCs and suggested a novel SPRY4ERK1/2-Wnt/ $\beta$-catenin regulatory loop, which plays a key role in cell adipogenic determination and in balancing of bone structure and homeostasis of bone marrow microenvironment [59].

GPR40/120 are receptors for both saturated and unsaturated fatty acids. It has been reported that a carboxylic group of the FFAs is required for GPR40 receptor activation. If the carboxylic group of FFAs is replaced by the methyl ester group, then the GPR40 receptor cannot be activated [60]. However, the relationship between the carboxylic group 
and GPR40 receptor activation has not been confirmed. Some studies showed that replacement of the carboxylic group with other different functional groups still can activate the GPR40/120 receptors $[31,61,62]$. In the present study, we demonstrated that PAME, which does not have carboxylic group, can still enhance adipogenic differentiation through activating GPR40/120. The $\alpha$-linolenic acid has been shown to stimulate the release of glucagon-like peptide-1 in cultured STC-1 intestinal endocrine cells and in mice and rats $[63,64]$. However, $\alpha$-linolenic acid is an agonist of both GPR120 and GPR40, which are both expressed in the intestine, and GPR40 has also been shown to mediate the glucagon-like peptide-1 release [65]. Although GPR40 and GPR120 share only 10\% homology between their amino acid sequences $[60,63]$, the binding activity of FAs to GPR120 and GPR40 is similar. Many of the natural agonists, such as EPA, DHA, and $\alpha$-linolenic acid, activate both receptors, making the difficulty to distinguish which of these two receptors contribute a specific biologic process [66-68].

In the present study, we demonstrated that PAME can promote MSC adipogeneic differentiation. MSCs play an important role in adipogenesis, which can lead to obesity [69]. It has been reported that adipose tissue secretes numerous adipokines and FFAs, thereby promoting MSC differentiation into adipocytes. Obese patients have significantly elevated PA levels in the blood [70]. A recent study reported that PAME is biosynthesized from PA via catechol-Omethyltransferase catalysis [37]. Moreover, a study has suggested that catechol-O-methyltransferase may participate in the development of obesity [71]. These findings suggest that more adipose tissue will synthesize and release more PAME, which in turn causes more MSCs to differentiate into adipocytes, forming a vicious circle.

\section{Conclusions}

The experimental findings presented in this paper introduce our basic observation that PAME can induce adipogenic differentiation through activating the GPR40/120-mediated signaling pathway. We propose a model of the molecular mechanism underlying PAME-enhanced adipogenic differentiation in rAD-MSCs as shown in Figure 6. Although in vivo studies of adipocyte-derived PAME promoting the adipogenic differentiation of MSC and leading to obesity are still ongoing, the findings from the present in vitro studies suggest that inhibition of the PAME activities may be a new direction for consideration in animal models of obesity to increase the possibility of future clinical applications.

\section{Data Availability}

All materials are available by the corresponding author.

\section{Conflicts of Interest}

The authors declare no conflicts of interest.

\section{Acknowledgments}

This study was supported by the Ministry of Science and Technology, Taiwan, Grant MOST 104-2320-B-320-015, and by Buddhist Tzu Chi Medical Foundation, Taiwan, Grant TCMMP 109-01-02. We thank the Core Facility of Tzu Chi University for the instruments and technical help.

\section{Supplementary Materials}

Supplement 1: treatment with GW1100 (5 $\mu \mathrm{M})$, AH7614 $(5 \mu \mathrm{M}), \mathrm{U} 73122(2 \mu \mathrm{M})$, or BAPTA-AM $(0.5 \mu \mathrm{M})$ in adipogenic induction medium for 12 days did not affect the activity of ERK1/2 (a) and the level of PPAR $\gamma$ (b) in rAD-MSCs. The top panel shows Western blot analysis; the lower panel shows a graph of quantitation of these data adjusted with their own total protein (a) or $\beta$-actin (b). Values present the means of fold of corresponding control \pm s.e.mean $(n=5)$. Treatment PAME $(50 \mu \mathrm{M})$ with $0.1 \%$ DMSO (Veh: vehicle), an antagonist solvent, in adipogenic induction medium for 12 days. The activity of ERK1/2 and the level of PPAR $\gamma$ were not significantly different between the AIM + PAME and the AIM+PAME+Veh in rAD-MSCs (c). (Supplementary Materials)

\section{References}

[1] K. Matsushita and V. J. Dzau, "Mesenchymal stem cells in obesity: insights for translational applications," Laboratory investigation; a journal of technical methods and pathology, vol. 97, no. 10, pp. 1158-1166, 2017.

[2] J. L. Knittle, K. Timmers, F. Ginsberg-Fellner, R. E. Brown, and D. P. Katz, "The growth of adipose tissue in children and adolescents. Cross-sectional and longitudinal studies of adipose cell number and size," The Journal of Clinical Investigation, vol. 63, no. 2, pp. 239-246, 1979.

[3] F. Ginsberg-Fellner and J. L. Knittle, "Weight reduction in young obese children. I. Effects on adipose tissue cellularity and metabolism," Pediatric Research, vol. 15, no. 10, pp. 1381-1389, 1981.

[4] J. Hirsch and B. Batchelor, "Adipose tissue cellularity in human obesity," Clinics in Endocrinology and Metabolism, vol. 5, no. 2, pp. 299-311, 1976.

[5] D. A. Roncari, D. C. Lau, and S. Kindler, "Exaggerated replication in culture of adipocyte precursors from massively obese persons," Metabolism, vol. 30, no. 5, pp. 425-427, 1981.

[6] W. P. Cawthorn, E. L. Scheller, and O. A. Mac Dougald, "Adipose tissue stem cells meet preadipocyte commitment: going back to the future[S]," Journal of Lipid Research, vol. 53, no. 2, pp. 227-246, 2012.

[7] L. Peng, Z. Jia, X. Yin et al., "Comparative analysis of mesenchymal stem cells from bone marrow, cartilage, and adipose tissue," Stem Cells and Development, vol. 17, no. 4, pp. 761774, 2008.

[8] X. Wei, X. Yang, Z. P. Han, F. F. Qu, L. Shao, and Y. F. Shi, "Mesenchymal stem cells: a new trend for cell therapy," Acta Pharmacologica Sinica, vol. 34, no. 6, pp. 747-754, 2013.

[9] R. Rohban and T. R. Pieber, "Mesenchymal stem and progenitor cells in regeneration: tissue specificity and regenerative potential," Stem Cells International, vol. 2017, 16 pages, 2017. 
[10] C. Lagathu, C. Christodoulides, C. Y. Tan et al., "Secreted frizzled-related protein 1 regulates adipose tissue expansion and is dysregulated in severe obesity," International Journal of Obesity, vol. 34, no. 12, pp. 1695-1705, 2010.

[11] S. Muruganandan, A. A. Roman, and C. J. Sinal, "Role of chemerin/CMKLR1 signaling in adipogenesis and osteoblastogenesis of bone marrow stem cells," Journal of Bone and Mineral Research: the Official Journal of the American Society for Bone and Mineral Research, vol. 25, no. 2, pp. 222-234, 2010.

[12] W. Yang, C. Yang, J. Luo, Y. Wei, W. Wang, and Y. Zhong, "Adiponectin promotes preadipocyte differentiation via the PPAR $\gamma$ pathway," Molecular Medicine Reports, vol. 17, no. 1, pp. 428-435, 2018.

[13] R. Yue, B. O. Zhou, I. S. Shimada, Z. Zhao, and S. J. Morrison, "Leptin receptor promotes adipogenesis and reduces osteogenesis by regulating mesenchymal stromal cells in adult bone marrow," Cell Stem Cell, vol. 18, no. 6, pp. 782-796, 2016.

[14] E. Y. Park, C. E. Yeum, G. Seo, J.-Y. Lee, S.-B. Lee, and G.T. Chae, "The adipogenic effect of palmitate in mouse bone marrow-derived mesenchymal stem cells," Tissue Engineering and Regenerative Medicine, vol. 10, no. 2, pp. 77-85, 2013.

[15] A. Casado-Díaz, R. Santiago-Mora, G. Dorado, and J. M. Quesada-Gómez, "The omega-6 arachidonic fatty acid, but not the omega-3 fatty acids, inhibits osteoblastogenesis and induces adipogenesis of human mesenchymal stem cells: potential implication in osteoporosis," Osteoporosis International, vol. 24, no. 5, pp. 1647-1661, 2013.

[16] J. Wang, Y. Liang, L. Jian et al., "Linoelaidic acid enhances adipogenic differentiation in adipose tissue-derived stromal cells through suppression of $\mathrm{Wnt} / \beta$-catenin signaling pathway _in vitro_," Prostaglandins, Leukotrienes, and Essential Fatty Acids, vol. 110, pp. 1-7, 2016.

[17] Y. C. Lee, H. H. Chang, C. L. Chiang et al., "Role of perivascular adipose tissue-derived methyl palmitate in vascular tone regulation and pathogenesis of hypertension," Circulation, vol. 124, no. 10, pp. 1160-1171, 2011.

[18] A. Rodríguez-Rivera, M. Galicia-Moreno, K. Reyes-Gordillo et al., "Methyl palmitate prevents $\mathrm{CCl}$ (4)-induced liver fibrosis," Journal of Applied Toxicology: JAT, vol. 28, no. 8, pp. 1021-1026, 2008.

[19] E. M. Mantawy, M. G. Tadros, A. S. Awad, D. A. Hassan, and E. El-Demerdash, "Insights antifibrotic mechanism of methyl palmitate: impact on nuclear factor kappa B and proinflammatory cytokines," Toxicology and Applied Pharmacology, vol. 258, no. 1, pp. 134-144, 2012.

[20] M. H. Sharawy, D. S. El-Agamy, A. A. Shalaby, and A. el SM, "Protective effects of methyl palmitate against silica-induced pulmonary fibrosis in rats," International Immunopharmacology, vol. 16, no. 2, pp. 191-198, 2013.

[21] E. El-Demerdash, "Anti-inflammatory and antifibrotic effects of methyl palmitate," Toxicology and Applied Pharmacology, vol. 254, no. 3, pp. 238-244, 2011.

[22] N. M. Saeed, E. El-Demerdash, H. M. Abdel-Rahman, M. M. Algandaby, F. A. Al-Abbasi, and A. B. Abdel-Naim, "Antiinflammatory activity of methyl palmitate and ethyl palmitate in different experimental rat models," Toxicology and Applied Pharmacology, vol. 264, no. 1, pp. 84-93, 2012.

[23] H. P. Zeng, T. T. Wang, W. Chen, C. Y. Wang, D. F. Chen, and J. G. Shen, "Characterization of chemical components in extracts from_Si-wu_ decoction with proliferationpromoting effects on rat mesenchymal stem cells," Bioorganic \& Medicinal Chemistry, vol. 16, no. 9, pp. 5109-5114, 2008.
[24] T. T. Wang, W. Chen, H. P. Zeng, and D. F. Chen, "Chemical components in extracts from Plastrum testudinis with proliferation-promoting effects on rat mesenchymal stem cells," Chemical Biology \& Drug Design, vol. 79, no. 6, pp. 1049-1055, 2012.

[25] J. H. Lin, P. C. Ting, W. S. Lee et al., "Palmitic Acid Methyl Ester Induces G2/M Arrest in Human Bone Marrow-Derived Mesenchymal Stem Cells via the p53/p21 Pathway," Stem Cells International, vol. 2019, Article ID 7606238, 15 pages, 2019.

[26] D.-K. Lee, T. Yi, K.-E. Park et al., "Non-invasive characterization of the adipogenic differentiation of human bone marrowderived mesenchymal stromal cells by HS-SPME/GC-MS," Scientific Reports, vol. 4, p. 6550, 2014.

[27] I. Kimura, A. Ichimura, R. Ohue-Kitano, and M. Igarashi, "Free fatty acid receptors in health and disease," Physiological Reviews, vol. 100, no. 1, pp. 171-210, 2020.

[28] A. Ichimura, A. Hirasawa, O. Poulain-Godefroy et al., "Dysfunction of lipid sensor GPR120 leads to obesity in both mouse and human," Nature, vol. 483, no. 7389, pp. 350-354, 2012.

[29] C. Gotoh, Y. H. Hong, T. Iga et al., "The regulation of adipogenesis through GPR120," Biochemical and Biophysical Research Communications, vol. 354, no. 2, pp. 591-597, 2007.

[30] B. Gao, Q. Huang, Q. Jie et al., “GPR120: a bi-potential mediator to modulate the osteogenic and adipogenic differentiation of BMMSCs," Scientific Reports, vol. 5, no. 1, article 14080, 2015.

[31] K. Mukherjee, S. Bhattacharyya, and P. Peralta-Yahya, "GPCR-based chemical biosensors for medium-chain fatty acids," ACS Synthetic Biology, vol. 4, no. 12, pp. 1261-1269, 2015.

[32] D. Ma, M. Zhang, C. P. Larsen et al., "DHA promotes the neuronal differentiation of rat neural stem cells transfected with GPR40 gene," Brain Research, vol. 1330, pp. 1-8, 2010.

[33] J. Chen, R. Crawford, C. Chen, and Y. Xiao, "The key regulatory roles of the PI3K/Akt signaling pathway in the functionalities of mesenchymal stem cells and applications in tissue regeneration," Tissue engineering Part B, Reviews, vol. 19, no. 6, pp. 516-528, 2013.

[34] J. Fukuda, E. Mizukami, and K. Imaichi, "Production of methyl esters of fatty acids as artifacts during the concentration of methanolic extracts of serum or plasma lipids," Journal of Biochemistry, vol. 61, no. 5, pp. 657-658, 1967.

[35] H. W. Lin, C. Z. Liu, D. Cao et al., "Endogenous methyl palmitate modulates nicotinic receptor-mediated transmission in the superior cervical ganglion," Proceedings of the National Academy of Sciences of the United States of America, vol. 105, no. 49, pp. 19526-19531, 2008.

[36] Y. C. Lee, H. H. Chang, C. H. Liu et al., "Methyl palmitate: a potent vasodilator released in the retina," Investigative Ophthalmology \& Visual Science, vol. 51, no. 9, pp. 4746-4753, 2010.

[37] C. H. Liu, H. J. Hsu, T. L. Tseng et al., "COMT-catalyzed palmitic acid methyl ester biosynthesis in perivascular adipose tissue and its potential role against hypertension," The Journal of Pharmacology and Experimental Therapeutics, vol. 373, no. 2, pp. 175-183, 2020.

[38] P. Cai, B. S. Kaphalia, and G. A. Ansari, "Methyl palmitate: inhibitor of phagocytosis in primary rat Kupffer cells," Toxicology, vol. 210, no. 2-3, pp. 197-204, 2005.

[39] S. Sarkar, M. F. Khan, B. S. Kaphalia, and G. A. Ansari, "Methyl palmitate inhibits lipopolysaccharide-stimulated 
phagocytic activity of rat peritoneal macrophages," Journal of Biochemical and Molecular Toxicology, vol. 20, no. 6, pp. 302-308, 2006.

[40] D. S. El-Agamy, M. A. Elkablawy, and H. M. Abo-Haded, "Modulation of cyclophosphamide-induced cardiotoxicity by methyl palmitate," Cancer Chemotherapy and Pharmacology, vol. 79, no. 2, pp. 399-409, 2017.

[41] D. J. Crankshaw, J. M. Walsh, and J. J. Morrison, “The effects of methyl palmitate, a putative regulator from perivascular fat, on the contractility of pregnant human myometrium," Life Sciences, vol. 116, no. 1, pp. 25-30, 2014.

[42] N. Wang, A. Kuczmanski, G. Dubrovska, and M. Gollasch, "Palmitic acid methyl ester and its relation to control of tone of human visceral arteries and rat aortas by perivascular adipose tissue," Frontiers in Physiology, vol. 9, p. 583, 2018.

[43] Y. Chi and X. You, "Kinetics of hydrogen abstraction reactions of methyl palmitate and octadecane by hydrogen atoms," The Journal of Physical Chemistry A, vol. 123, no. 14, pp. 30583067, 2019.

[44] A. K. Jain, K. Allton, M. Iacovino et al., "p53 regulates cell cycle and MicroRNAs to promote differentiation of human embryonic stem cells," PLoS Biology, vol. 10, no. 2, article e1001268, 2012.

[45] N. Inoue, N. Yahagi, T. Yamamoto et al., "Cyclin-dependent Kinase Inhibitor, p $21^{\mathrm{WAF} 1 / \mathrm{CIP} 1}$, Is Involved in Adipocyte Differentiation and Hypertrophy, Linking to Obesity, and Insulin Resistance," The Journal of Biological Chemistry, vol. 283, no. 30, pp. 21220-21229, 2008.

[46] Y. Liu, R. Zhang, J. Xin et al., "Identification of S100A16 as a novel adipogenesis promoting factor in 3T3-L1 cells," Endocrinology, vol. 152, no. 3, pp. 903-911, 2011.

[47] Q. Huang, M. Liu, X. Du et al., "Role of p 53 in preadipocyte differentiation," Cell Biology International, vol. 38, no. 12, pp. 1384-1393, 2014.

[48] A. Molchadsky, O. Ezra, P. G. Amendola et al., "p53 is required for brown adipogenic differentiation and has a protective role against diet-induced obesity," Cell Death and Differentiation, vol. 20, no. 5, pp. 774-783, 2013.

[49] G. S. Wu, "The functional interactions between the MAPK and p53 signaling pathways," Cancer Biology \& Therapy, vol. 3, no. 2, pp. 156-161, 2004.

[50] D. V. Zosen and M. V. Glazova, "The role of the interaction of p 53 and the MAPK cascade in controlling neuronal differentiation in the PC12 cell line," Neuroscience and Behavioral Physiology, vol. 46, no. 5, pp. 559-565, 2016.

[51] D. Prusty, B. H. Park, K. E. Davis, and S. R. Farmer, "Activation of MEK/ERK Signaling Promotes Adipogenesis by Enhancing Peroxisome Proliferator-activated Receptor $\gamma$ $(\operatorname{PPAR} \gamma)$ and $\mathrm{C} / \mathrm{EBP} \alpha$ Gene Expression during the Differentiation of 3T3-L1 Preadipocytes," The Journal of Biological Chemistry, vol. 277, no. 48, pp. 46226-46232, 2002.

[52] L. Wu, X. Cai, H. Dong et al., "Serum regulates adipogenesis of mesenchymal stem cells via MEK/ERK-dependent PPAR $\gamma$ expression and phosphorylation," Journal of Cellular and Molecular Medicine, vol. 14, no. 4, pp. 922-932, 2010.

[53] E. Donzelli, C. Lucchini, E. Ballarini et al., "ERK1 and ERK2 are involved in recruitment and maturation of human mesenchymal stem cells induced to adipogenic differentiation," Journal of Molecular Cell Biology, vol. 3, no. 2, pp. 123-131, 2011.
[54] H. Shi, H. Y-D, P. N. Ellis, W. O. Wilkison, and M. B. Zemel, "Role of intracellular calcium in human adipocyte differentiation," Physiological Genomics, vol. 3, no. 2, pp. 75-82, 2000.

[55] Y. K. Bae, J. H. Kwon, M. Kim et al., "Intracellular Calcium Determines the Adipogenic Differentiation Potential of Human Umbilical Cord Blood-Derived Mesenchymal Stem Cells via the Wnt5a/ $\beta$-Catenin Signaling Pathway," Stem Cells International, vol. 2018, Article ID 6545071, 17 pages, 2018.

[56] W. Gao, P. Zhou, X. Ma et al., "Ethanol negatively regulates hepatic differentiation of hESC by inhibition of the MAPK/ERK signaling pathway in vitro," PLoS One, vol. 9, no. 11, article e112698, 2014.

[57] T. Zhang, H. Chen, Y. Zhou, W. Dong, H. Cai, and W.-S. Tan, "Cooperation of FGF/MEK/ERK and Wnt/ $\beta$-catenin pathway regulators to promote the proliferation and pluripotency of mouse embryonic stem cells in serum- and feeder-free conditions," Bioresources and Bioprocessing, vol. 6, no. 1, p. 12, 2019.

[58] K. Dzobo, M. Vogelsang, and M. I. Parker, "Wnt/ $\beta$-catenin and MEK-ERK signaling are required for fibroblast-derived extracellular matrix-mediated endoderm differentiation of embryonic stem cells," Stem Cell Reviews and Reports, vol. 11, no. 5, pp. 761-773, 2015.

[59] L. Tian, H. Xiao, M. Li et al., "A novel Sprouty4-ERK1/2$\mathrm{Wnt} / \beta$-catenin regulatory loop in marrow stromal progenitor cells controls osteogenic and adipogenic differentiation," Metabolism, vol. 105, article 154189, 2020.

[60] Y. Itoh, Y. Kawamata, M. Harada et al., "Free fatty acids regulate insulin secretion from pancreatic $\beta$ cells through GPR40," Nature, vol. 422, no. 6928, pp. 173-176, 2003.

[61] Z. Li, Z. Zhou, and L. Zhang, "Current status of GPR40/FFAR1 modulators in medicinal chemistry (2016-2019): a patent review," Expert Opinion on Therapeutic Patents, vol. 30, no. 1, pp. 27-38, 2020.

[62] M. M. Yore, I. Syed, P. M. Moraes-Vieira et al., "Discovery of a class of endogenous mammalian lipids with anti-diabetic and anti-inflammatory effects," Cell, vol. 159, no. 2, pp. 318-332, 2014.

[63] A. Hirasawa, K. Tsumaya, T. Awaji et al., "Free fatty acids regulate gut incretin glucagon-like peptide-1 secretion through GPR120," Nature Medicine, vol. 11, no. 1, pp. 90-94, 2005.

[64] S. Miyauchi, A. Hirasawa, T. Iga et al., "Distribution and regulation of protein expression of the free fatty acid receptor GPR120," Naunyn-Schmiedeberg's Archives of Pharmacology, vol. 379, no. 4, pp. 427-434, 2009.

[65] L. W. Christensen, R. E. Kuhre, C. Janus, B. Svendsen, and J. J. Holst, "Vascular, but not luminal, activation of FFAR1 (GPR40) stimulates GLP-1 secretion from isolated perfused rat small intestine," Physiological Reports, vol. 3, no. 9, p. e12551, 2015.

[66] K. Mobraten, T. M. Haug, C. R. Kleiveland, and T. Lea, "Omega-3 and omega-6 PUFAs induce the same GPR120mediated signalling events, but with different kinetics and intensity in Caco-2 cells," Lipids in Health and Disease, vol. 12, no. 1, p. 101, 2013.

[67] J. M. Houthuijzen, "For better or worse: FFAR1 and FFAR4 signaling in cancer and diabetes," Molecular Pharmacology, vol. 90, no. 6, pp. 738-743, 2016.

[68] J. Miyamoto, S. Hasegawa, M. Kasubuchi, A. Ichimura, A. Nakajima, and I. Kimura, "Nutritional signaling via free fatty acid receptors," International Journal of Molecular Sciences, vol. 17, no. 4, p. 450, 2016. 
[69] L. S. Baptista, K. R. Silva, and R. Borojevic, "Obesity and weight loss could alter the properties of adipose stem cells?,"World journal of stem cells, vol. 7, no. 1, pp. 165-173, 2015.

[70] J. Korbecki and K. Bajdak-Rusinek, "The effect of palmitic acid on inflammatory response in macrophages: an overview of molecular mechanisms," Inflammation Research, vol. 68, no. 11, pp. 915-932, 2019.

[71] K. Annerbrink, L. Westberg, S. Nilsson, R. Rosmond, G. Holm, and E. Eriksson, "Catechol_O_-methyltransferase val158-met polymorphism is associated with abdominal obesity and blood pressure in men," Metabolism, vol. 57, no. 5, pp. 708-711, 2008. 